\title{
REPROVAÇÃO INDUZ EVASÃO? ASPECTOS DA TRAJETÓRIA ACADÊMICA NO CURSO DE MATEMÁTICA-LICENCIATURA EM UMA INSTITUIÇÃO FEDERAL DE EDUCAÇÃO SUPERIOR
}

\author{
Does failure lead to dropout? Aspects of the academic trajectory in the Mathematics \\ Degree course at a federal institution of Higher Education
}

\section{¿Reprobación induce abandono? Aspectos de la trayectoria académica en el curso de Licenciatura en Matemáticas en una institución federal de Educación Superior}

\author{
José da Silva Santos Junior* \\ Giselle Cristina Martins Real ${ }^{* *}$
}

\begin{abstract}
Resumo
O objetivo é analisar aspectos relacionados à trajetória acadêmica no contexto do curso de Matemática-Licenciatura da Universidade Federal da Grande Dourados (UFGD), com vistas a verificar se e como os processos de reprovação e evasão se articulam. A pesquisa é exploratória e de caráter quanti-qualitativo, recorrendo-se a dados de trajetória acadêmica fornecidos pela instituição, referentes aos alunos ingressantes por Processo Seletivo Vestibular entre os anos de 2006 e 2009. Procurou-se responder a seguinte questão norteadora: há relação entre reprovação e evasão no curso de Matemática-Licenciatura da UFGD? Os resultados indicam que há tendência de ampliação da permanência prolongada com o passar dos anos, acompanhada de dados expressivos de evasão (em torno de 70\%). As reprovações em disciplinas específicas do curso se mostraram significativas, o que contribuiu para inferir que correspondem a um fator determinante para a evasão, sobretudo por observar que os maiores percentuais deste fenômeno ocorreram no primeiro ano do curso. Ainda, reprovações sucessivas também contribuíram para a evasão de estudantes em permanência prolongada. Nesse contexto, indica-se pela realização de novas pesquisas de caráter longitudinal e qualitativo.
\end{abstract}

PALAVRAS-CHAVE: Evasão. Reprovação. Educação Superior. Política educacional.

\begin{abstract}
The objective is to analyze aspects related to the academic trajectory in the context of the Mathematics Degree course at the Federal University of Grande Dourados (UFGD), with a view to verifying whether and how the processes of failure and dropout are articulated. The research is exploratory and of a quanti-qualitative character, which follows the data of academic trajectory applied by the institution, including incoming students by Vestibular Selection Process between the years 2006 and 2009. The answer was proceeded from the following topic: are there relationship between failure and dropout in the Mathematics Degree course at UFGD? The results indicate that there is a tendency to increase the length of stay over the years, accompanied by significant dropout data (around 70\%). Failures in specific subjects of the course were significant, which contributes to infer it is a determining factor of dropout, mainly by observing what the highest percentages of this phenomenon occurred in the first year of the course. Still, successive failures also contributed to the dropout of students in prolonged stay. In this context, it indicates the realization of new longitudinal and qualitative research.
\end{abstract}

\footnotetext{
* Mestre em Educação. Técnico em Educação de Nível Superior vinculado à Universidade Federal da Grande Dourados (UFGD). E-mail: josejunior_ss@yahoo.com.br. Orcid: https://orcid.org/0000-0001-6268-0062 *** Doutora em Educação. Docente vinculada à Universidade Federal da Grande Dourados (UFGD). E-mail: gisellereal@ufgd.edu.br. Orcid: https://orcid.org/0000-0002-8855-4141
} 
KEYWORDS: Dropout. Failure. Higher Education. Educational policy.

\section{Resumen}

El objetivo es analizar aspectos relacionados con la trayectoria académica en el contexto del curso de Licenciatura en Matemáticas en la Universidad Federal de Grande Dourados (UFGD), a fin de verificar si y cómo se articulan los procesos de reprobación y abandono. La investigación es exploratoria y de carácter cuantitativo, utilizando datos de la trayectoria académica proporcionada por la institución, en referencia a los estudiantes que ingresaron a través del Proceso de Selección Vestibular entre los años 2006 y 2009. Intentamos responder la siguiente pregunta guía: ¿existe una relación? Entre la reprobación y lo abandono en el curso de Matemáticas-Graduación en UFGD? Los resultados indican que existe una tendencia a aumentar la duración de la permanencia a lo largo de los años, acompañada de datos significativos de abandono (alrededor del 70\%). Las reprobaciones en materias específicas del curso resultaron ser significativas, lo que contribuyó a inferir que corresponden a un factor determinante de abandono, sobre todo al observar que los porcentajes más altos de este fenómeno ocurrieron en el primer año del curso. Aún así, las reprobaciones sucesivas también contribuyeron a lo abandono de los estudiantes en permanencias prolongadas. En este contexto, se indica la realización de más investigaciones longitudinales y cualitativas.

PALABRAS CLAVE: Abandono. Reprobación. Educación universitaria. Política educativa.

\section{INTRODUÇÃO}

O objetivo do presente trabalho é analisar aspectos relacionados à trajetória acadêmica no contexto do curso de Matemática-Licenciatura da Universidade Federal da Grande Dourados (UFGD), com vistas a verificar se e como os processos de reprovação e evasão se articulam.

A opção por este curso se deu em função de se configurar como o de maior percentual de evasão entre 2006 e 2009 na instituição locus de pesquisa, conforme apontado no estudo de Santos Junior e Real (2017), os quais constataram uma média de evasão de 70,3\% no período, obtida a partir da metodologia de trajetória escolar ${ }^{1}$.

A literatura vem registrando estudos que discutem algumas nuances relacionadas ao curso de Matemática no Brasil, abordando, por exemplo, questões concernentes à formação do licenciado (MANRIQUE, 2009) e à evasão acadêmica (BITTAR et al., 2012; SANTOS, 2012). Na mesma direção, outros pesquisadores também encontraram resultados que ranquearam o curso de Matemática dentre aqueles com percentuais mais elevados de evasão no Brasil (ADACHI, 2009; SAMPAIO et al., 2011; SILVA FILHO et al., 2007).

No estudo de Silva Filho et al. (2007), com a utilização de dados do Censo da Educação Superior, o curso de Matemática é registrado com taxa média de evasão ${ }^{2}$ de $44 \%$ no ano de 2005, se tratando da maior taxa dentre o conjunto de cursos superiores ofertados no País.

Em um contexto geograficamente mais próximo ao da presente pesquisa e com a análise de dados realizada a partir de dados fornecidos pela própria instituição, Bittar et al. (2012) analisaram o fenômeno da evasão no curso de Matemática da Universidade Federal de Mato Grosso do Sul (UFMS), apresentando resultados que envolveram trinta anos de funcionamento do curso na referida instituição. Observaram que em toda a história da

\footnotetext{
${ }^{1} \mathrm{O}$ levantamento de dados institucionais que compuseram a pesquisa foi realizado no primeiro semestre letivo do ano de 2015.

${ }^{2}$ Para o cálculo de evasão, os autores se valeram de dados das Sinopses Estatísticas da Educação Superior, utilizando a seguinte metodologia de cálculo: $\mathrm{E}_{(\mathrm{n})}=1-\left[\left(\mathrm{M}_{(\mathrm{n})}-\mathrm{I}_{(\mathrm{n})} /\left(\mathrm{M}_{(\mathrm{n}-1)}-\left(\mathrm{C}_{(\mathrm{n}-1)}\right]\right.\right.\right.$ Onde, $\mathrm{E}_{(\mathrm{n})}=$ evasão anual de cursos ou do conjunto de cursos (no ano $n$ ); $M_{(n)}=$ matrículas (no ano $n$ ); $I_{(n)}=$ ingressantes (no ano $n$ ); $\mathrm{M}_{(\mathrm{n}-1)}=$ matrículas do ano anterior a $\mathrm{n} ; \mathrm{C}_{(\mathrm{n}-1)}=$ concluintes do ano anterior $\mathrm{a} \mathrm{n}$.
} 
universidade cerca de $20 \%$ dos alunos ingressantes foram diplomados. Isto é, a média de evasão esteve em torno de $80 \%$.

Assim, ao optar por discutir alguns fatores relacionados a não permanência no curso de Matemática-Licenciatura da UFGD é preciso ter a clareza de que o pano de fundo se sustenta em problemáticas de contextos mais amplos. Desse modo, o presente trabalho indagou sobre possíveis fatores que se alocam no âmbito institucional, especificamente, sobre a possível relação entre reprovação e evasão.

A evasão é entendida no presente artigo a partir do conceito de "evasão de curso", em que o aluno é considerado evadido quando se desliga do curso superior em situações diversas tais como abandono, desistência, transferência ou reopção, exclusão por norma institucional (BRASIL, 1997). A reprovação é analisada como a não aprovação em componentes curriculares do curso investigado.

Nos aspectos metodológicos, o estudo se configura como de trajetória acadêmica ${ }^{3}$, em que se analisa caso a caso a situação dos estudantes ingressantes, os quais podem encontrar-se no momento da pesquisa como concluinte, em permanência prolongada ${ }^{4}$ ou evadido. Trata-se de uma pesquisa exploratória e de caráter quanti-qualitativo, tendo em vista que se recorreu a dados estatísticos fornecidos pela instituição referentes aos alunos ingressantes por Processo Seletivo Vestibular entre os anos de 2006 e 2009.

Pretende-se responder a seguinte questão norteadora: há relação entre reprovação e evasão no curso de Matemática-Licenciatura da UFGD?

O trabalho está estruturado em três seções. Na primeira delas expõe-se o contexto de implementação do curso de Matemática na UFGD, apresentando algumas características e alterações curriculares ocorridas durante o recorte temporal da presente pesquisa. A segunda seção é destinada à apresentação de dados de evasão no curso. Na terceira seção busca-se analisar como se apresentaram, numericamente, as reprovações em disciplinas do curso e, a partir disso, identificar se este foi um fator relevante para a ocorrência do fenômeno da evasão.

\section{O contexto do curso de Matemática na UFGD}

A UFGD foi criada em julho de 2005 por desmembramento do Campus de Dourados da Universidade Federal de Mato Grosso do Sul (UFMS), sendo este um dos resultados da política governamental de interiorização da educação superior ocorrida na década de 2000, em contraposição a uma assimetria de distribuição de vagas nas diversas regiões que compõem o País (ARAÚJO, 2016).

Quando iniciados os trabalhos na recém-criada universidade, o curso de Matemática-Licenciatura já existia na instituição, uma vez que fora criado a partir da Resolução 17 do Conselho Universitário da UFMS no ano de 1986 (UFGD, 1988, 1989, 1990).

Uma das justificativas para a implementação do curso na instituição relacionava-se à sua necessidade social, o que abarcava a possibilidade de suprimir parcialmente a demanda pela formação de professores de Matemática da educação básica na região sul do estado de Mato Grosso do Sul. Em consequência disso, nos anos subsequentes ao início da oferta da licenciatura em Matemática, compreendendo as décadas de 1990 e 2000, começaram a ser formuladas alterações e reestruturações para o curso, implementadas com o intuito de acompanhar as reformas que vinham ocorrendo na educação brasileira.

\footnotetext{
${ }^{3}$ Foi analisada a situação dos estudantes no primeiro semestre letivo de 2015.

${ }^{4}$ Fenômeno compreendido no presente trabalho como a permanência do estudante para além do tempo considerado como ideal para a conclusão do curso.
} 
Propunha-se, em um contexto mais amplo, consolidar a instituição no cenário regional e nacional, sobretudo nos aspectos relacionados à sua atuação social, dado que a formação de licenciados em Matemática, bem como em outras licenciaturas, estava imbricada com a necessidade de profissionais para as escolas de educação básica da região em que a IES se encontra e do País (UFGD, 2003).

No contexto da década de 2000, que se tratou de período importante para o processo de expansão da educação superior brasileira (NUNES; VELOSO, 2016), as modificações implantadas no curso de Matemática da UFGD almejavam, em última instância, "[...] formar o educador matemático, tendo como horizonte de sua formação a educação, em sentido amplo, e o ensino de matemática como eixo problematizador desta formação" (UFGD, 2003, p. 19).

Com a criação da UFGD, em 2005, o curso continuou em funcionamento ${ }^{5}$, a priori, com o mesmo objetivo traçado anteriormente, visto que o seu Projeto Pedagógico foi reformulado um ano antes da criação da nova universidade e esteve em vigência até o ano de 2008, quando foi novamente reestruturado.

O currículo do curso construído e implementado a partir de 2004, pensado para um tempo de integralização de quatro anos, contava com um total de 3.082 horas, apresentando-se dividido em disciplinas partindo de eixos mais amplos envolvendo conteúdos de formação específica, formação pedagógica, cultura geral e profissional e dimensão prática.

Esta configuração curricular esteve em vigência entre os anos de 2004 e 2008, adequando-se às normatizações propostas pelas Resoluções CNE/CP n ${ }^{\text {s }} 01$ e 02 de 2002, e pelas Diretrizes Curriculares Nacionais para o curso de Matemática, expressas na Resolução CNE/CES $n^{\circ} 03$ de 2003. Tais normativas culminaram na reformulação do curso de Matemática-Licenciatura da UFGD, possibilitando uma maior articulação entre teoria e prática, a partir da oferta de conteúdos e atividades acadêmico-científico-culturais e da realização de 400 horas de estágio supervisionado.

As disciplinas por ano do curso referentes a cada um dos componentes curriculares são retratadas no quadro 01 .

Quadro 01 - Relação de componentes curriculares por série, ofertados no curso de Matemática. UFGD.

\begin{tabular}{|c|c|c|c|c|c|}
\hline \multicolumn{6}{|c|}{ 2004-2008 } \\
\hline & $\begin{array}{c}{ }^{6} \text { Conteúdo de } \\
\text { Formação Específica }\end{array}$ & $\begin{array}{l}\text { Conteúdo de } \\
\text { Formação } \\
\text { Pedagógica }\end{array}$ & $\begin{array}{c}\text { Conteúdo de } \\
\text { cultura geral e } \\
\text { profissional }\end{array}$ & $\begin{array}{c}\text { Conteúdo de } \\
\text { dimensão } \\
\text { prática }\end{array}$ & $\begin{array}{l}\text { Conteúdo de } \\
\text { formação } \\
\text { geral } \\
\end{array}$ \\
\hline $\begin{array}{c}1^{\mathrm{a}} \\
\text { SÉRIE }\end{array}$ & $\begin{array}{l}\text { - Construções } \\
\text { Geométricas; } \\
\text { - Fundamentos de } \\
\text { Cálculo; } \\
\text { - Matemática e } \\
\text { Aplicações; } \\
\text { - Matemática Elementar } \\
\text { Aplicada; } \\
\text { - Vetores e Geometria } \\
\text { Analítica Plana. }\end{array}$ & $\begin{array}{l}-\quad \text { Estrutura e } \\
\text { Funcionamento da } \\
\text { Educação Básica. }\end{array}$ & ---- & $\begin{array}{ll}\text { - Prática } & \text { de } \\
\text { Ensino } & \text { de } \\
\text { Matemática I. } & \end{array}$ & ---- \\
\hline $\begin{array}{c}2^{\mathrm{a}} \\
\text { SÉRIE }\end{array}$ & $\begin{array}{l}\text { - Álgebra I; } \\
\text { - Álgebra Linear; } \\
\text { - Cálculo Diferencial e }\end{array}$ & $\begin{array}{ll}\text { - Didática } & \text { do } \\
\text { Ensino } & \text { da } \\
\text { Matemática; } & \end{array}$ & $\begin{array}{l}\text { - Tecnologia e } \\
\text { Educação. }\end{array}$ & $\begin{array}{ll}\text { - Prática de } \\
\text { Ensino } \\
\text { Matemática II. }\end{array}$ & ---- \\
\hline
\end{tabular}

\footnotetext{
${ }^{5} \mathrm{O}$ curso de Matemática-Licenciatura foi ofertado no período matutino entre os anos investigados, com oferta de 50 vagas nos processos seletivos de 2006 e 2008 e de 51 vagas em 2009.

${ }^{6}$ A classificação dos componentes curriculares de acordo com o conteúdo é dada pelo projeto pedagógico em vigência no curso de Matemática no período exposto.
} 


\begin{tabular}{|c|c|c|c|c|c|}
\hline & $\begin{array}{l}\text { Integral I; } \\
\text { - Vetores e Geometria } \\
\text { Analítica Espacial. }\end{array}$ & $\begin{array}{l}\text { - Psicologia do } \\
\text { Desenvolvimento e } \\
\text { da Aprendizagem }\end{array}$ & & & \\
\hline $\begin{array}{l}3^{\mathrm{a}} \\
\text { SÉRIE }\end{array}$ & $\begin{array}{l}\text { - Álgebra II; } \\
\text { - Cálculo Diferencial e } \\
\text { Integral II; } \\
\text { - Física I. }\end{array}$ & $\begin{array}{ll}\text { Especial. } & \text { Educação } \\
\text { Es }\end{array}$ & ---- & $\begin{array}{l}-\quad \text { Prática de } \\
\text { Ensino de de } \\
\text { Matemática III; } \\
-\quad \text { Estágio } \\
\text { Supervisionado } \\
\text { no Ensino } \\
\text { Fundamental. }\end{array}$ & $\begin{array}{l}\text { - Elementos } \\
\text { de Geometria }\end{array}$ \\
\hline $\begin{array}{c}4^{\mathrm{a}} \\
\text { SEERIE }\end{array}$ & - Física II; & $\begin{array}{lr}\quad \text { Sociologia } & \text { e } \\
\text { Política } & \text { da } \\
\text { Educação. } & \end{array}$ & ---- & $\begin{array}{l}-\quad \text { Prática de } \\
\text { Ensino de } \\
\text { Matemática IV; } \\
-\quad \text { Estágio } \\
\text { Supervisionado } \\
\text { no } \quad \text { Ensino } \\
\text { Médio. }\end{array}$ & $\begin{array}{l}\text { - Introdução } \\
\text { à Análise } \\
\text { Real; } \\
-\quad \text { Análise } \\
\text { Combinatória } \\
\text { e Estatística } \\
\text { Descritiva; } \\
\text { - Introdução } \\
\text { à História da } \\
\text { Matemática. }\end{array}$ \\
\hline
\end{tabular}

Fonte: UFGD, 2003, p. 53-54.

A disposição curricular do curso de Matemática da UFGD, expressa no Quadro 01, passou por novas alterações com o passar dos anos. Em 2009, com a adesão da UFGD ao Programa de Apoio a Planos de Reestruturação e Expansão das Universidades Federais (Reuni), além de mudanças no regime de matrícula, que passou de anual seriado para o regime de crédito semestral, as alterações curriculares do curso de MatemáticaLicenciatura foram realizadas tendo como um dos intuitos possibilitar uma formação mais ampla dos sujeitos, com foco em uma construção transdisciplinar do currículo.

A elaboração da matriz curricular a partir deste período, articulada às metas do projeto criado pela UFGD para o Reuni, visou à implementação de um regime acadêmico amplo, dinâmico e flexível, o que possibilitaria ao aluno maior autonomia na construção de sua própria grade curricular, contemplando, ainda, maiores possibilidades de mobilidade acadêmica intra-institucional (UFGD, 2008).

O aluno cumpriria nos primeiros períodos de formação $25 \%$ da carga horária em disciplinas comuns a todos os cursos da instituição e poderia, também, realizar $10 \%$ da carga horária total em disciplinas eletivas de qualquer curso ou campo do conhecimento (UFGD, 2008).

Nesse sentido, os ajustes curriculares possibilitaram aos alunos ingressantes a partir de 2009 obterem uma formação mais humanista e transdisciplinar, uma vez que, além de se matricularem em disciplinas específicas (1.512 horas), para a integralização do curso seria necessário cumprir créditos em disciplinas eletivas (360 horas), bem como em componentes do eixo de formação comum à área (432 horas) e do eixo temático de formação comum à universidade (432 horas), em que este último envolveria temáticas diversas, como cidadania, meio ambiente, saúde e sexualidade. Ainda, para concluir o curso fazia-se necessário cumprir 486 horas em estágio curricular supervisionado, 72 horas em trabalho de conclusão do curso e 240 horas em atividades complementares, totalizando uma carga horária de 3.534 horas para o curso (UFGD, 2008).

Cumpre ressaltar que as disciplinas ofertadas até o ano de 2008, apresentadas no quadro 01, foram alteradas e adaptadas para a nova realidade do curso a partir de 2009. As alterações se deram tanto nos aspectos de cargas horárias quanto em relação ao ementário dos componentes curriculares, bem como com a inclusão de outros componentes, mais voltados para a formação geral dos estudantes. 
Ao que se percebe, o objetivo maior destas alterações foi de possibilitar uma adaptação satisfatória da estrutura vigente até 2008 para as diretrizes do programa Reuni, que dada a sua influência e relevância incitou a reestruturação de todos os cursos da UFGD a partir de 2009.

Desse modo, apreciou-se um processo contínuo de reestruturações no âmbito do curso de graduação da UFGD, em que o período de criação da instituição e de implementação do curso de Matemática-Licenciatura coincidiu com o estabelecimento de políticas mais amplas do contexto nacional, o que contribuiu para o aprimoramento e a consolidação do referido curso.

\section{Reprovação e evasão no curso de Matemática da UFGD}

O curso de Matemática-Licenciatura adquiriu destaque quando se analisou algumas particularidades da trajetória acadêmica na UFGD (SANTOS JUNIOR; REAL, 2017), tendo em vista que no contexto geral dos cursos, apresentou elevada taxa de evasão e baixo percentual de conclusão ${ }^{7}$, conforme pode ser observado na Tabela 01:

Tabela 01 - Percentuais gerais de evasão e conclusão das turmas ingressantes via vestibular no curso de Matemática da UFGD entre 2006 e 2009

\begin{tabular}{cccc}
\hline Anos & Percentual de evasão & $\begin{array}{c}\text { Permanência } \\
\text { prolongada }\end{array}$ & Percentual de conclusão \\
\hline $\mathbf{2 0 0 6}$ & 71,9 & 0 & 28,1 \\
$\mathbf{2 0 0 7}$ & 71,7 & 2,2 & 26,1 \\
$\mathbf{2 0 0 8}$ & 73,1 & 1,9 & 23,1 \\
$\mathbf{2 0 0 9}$ & 64,6 & 14,6 & 18,8 \\
\hline
\end{tabular}

Fonte: Elaboração própria a partir dos dados coletados na pesquisa.

Constata-se oscilação dos números referentes à evasão, com uma média geral próxima de $70 \%$ no período analisado. Por outro lado, verifica-se diminuição no número de concluintes no decorrer dos anos, sendo acompanhado de um aumento importante de estudantes em permanência prolongada em 2009, o que indica que há tendência de evolução dos percentuais de estudantes retidos no curso.

Antes de aprofundar nessa questão, um ponto que merece atenção nos estudos de evasão se trata do momento em que o estudante evade. O Gráfico 01 apresenta, dentre o conjunto de estudantes evadidos, os percentuais de evasão em cada período do curso.

Gráfico 01 - Percentuais de evasão por período dos alunos ingressantes via vestibular no curso de Matemática. UFGD. 2006-2009

\footnotetext{
${ }^{7}$ Os dados que seguem na seção foram obtidos a partir de análise da trajetória dos estudantes, analisando-se caso a caso a situação acadêmica dos estudantes, procurando-se verificar quantos evadiram e quantos concluíram o curso.
} 


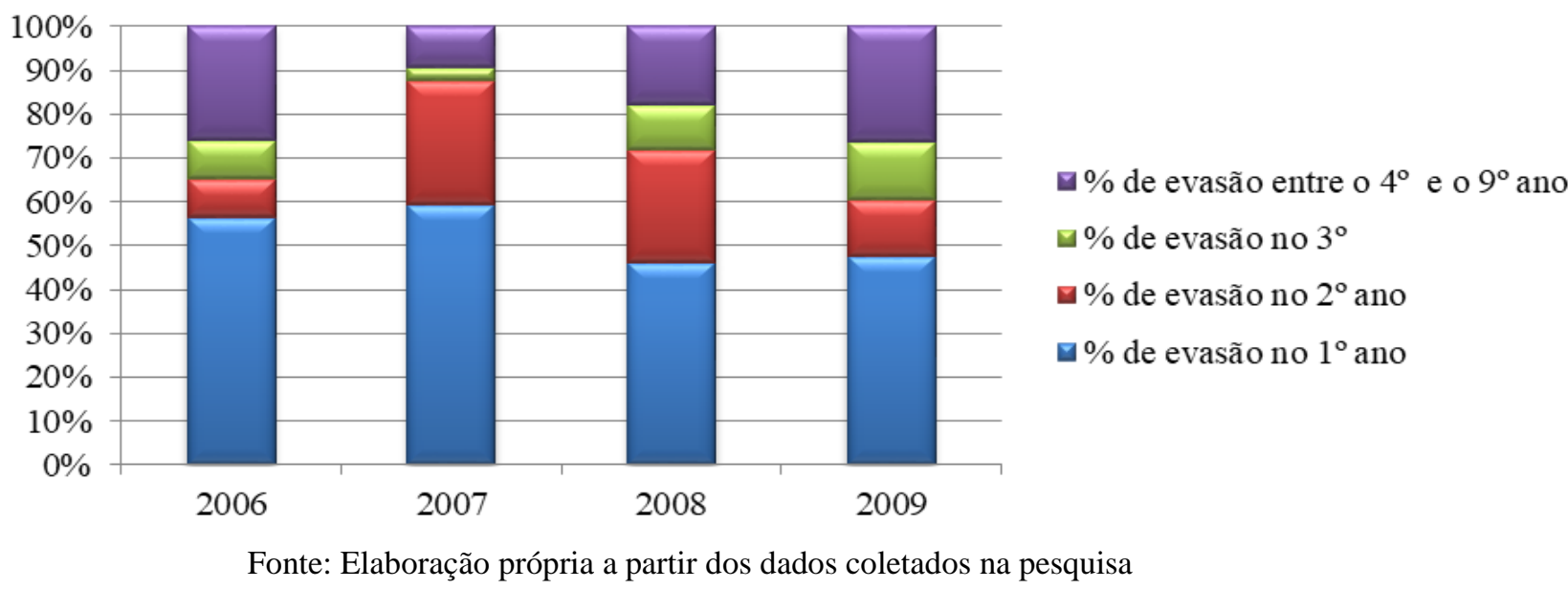

Em análise individual, do total de estudantes evadidos durante todo o período de duração do curso, os percentuais daqueles que evadem entre o primeiro e o segundo ano são: 56,5\% em 2006, 60,6\% em 2007, 47,4\% em 2008 e 51,6\% em 2009.

Por outro lado, embora oscilante, verifica-se que aproximadamente uma média de $20 \%$ dos estudantes evadiu após o quarto ano de curso. Este dado explicita que a permanência prolongada também pode corresponder a um dos fatores que engendra a evasão, em que parte dos estudantes se mantém no curso por um período expressivo de tempo e então decide por evadir-se.

Os achados de pesquisa relacionados à elevada evasão nos primeiros períodos, à ascensão do processo de permanência prolongada no decorrer dos anos e à incidência de abandono, também, vários semestres após o ingresso, se tratam de variáveis relevantes para a trajetória do estudante no curso, podendo ainda se tratar de fatores interligados. Para Silva, Lameira e Barbosa (2014) "retenção e evasão guardam similaridades entre si principalmente quanto às causas que as promove, e quanto aos impactos que geram nas diferentes etapas do processo educativo" (p. 03).

A articulação entre tais fenômenos caracteriza um processo de contradições, visto que sua decorrência ruma na direção contrária dos objetivos traçados para a educação superior no âmbito da expansão deste nível de ensino no País, em que o resultado esperado seria a diplomação dos estudantes.

Para Silva N. M. (2012) a reprovação e a evasão se articulam ao insucesso estudantil, definido como a situação em que "[...] o estudante reprova e repete componentes curriculares e/ou disciplinas, abandona ou evade do curso de graduação" (SILVA N. M., 2012, p. 56).

Para o caso do curso de Matemática-Licenciatura, a questão associada à reprovação se configura como um ponto importante para os estudos de trajetória acadêmica, visto que o referido curso, em um contexto nacional, apresenta taxas elevadas desse processo, sobretudo em componentes curriculares específicos das Ciências Exatas (RAFAEL; ESCHER, 2015).

\section{Reprovações nos componentes curriculares do curso de Matemática-Licenciatura da UFGD}

Quando se analisou que o fenômeno da evasão foi mais intenso nos primeiros períodos (gráfico 01), tornou-se oportuno o levantamento de dados referentes às taxas de 
reprovação nos componentes curriculares ofertados no primeiro ano do curso de Matemática da UFGD entre 2006 e 2009.

O Gráfico 02 expressa os $\operatorname{dados}^{8}$ obtidos para o período de 2006 a 2008:

Gráfico 02 - Percentuais de aprovação e de reprovação em disciplinas ofertadas no primeiro ano do curso de Matemática. UFGD. 2006-2008

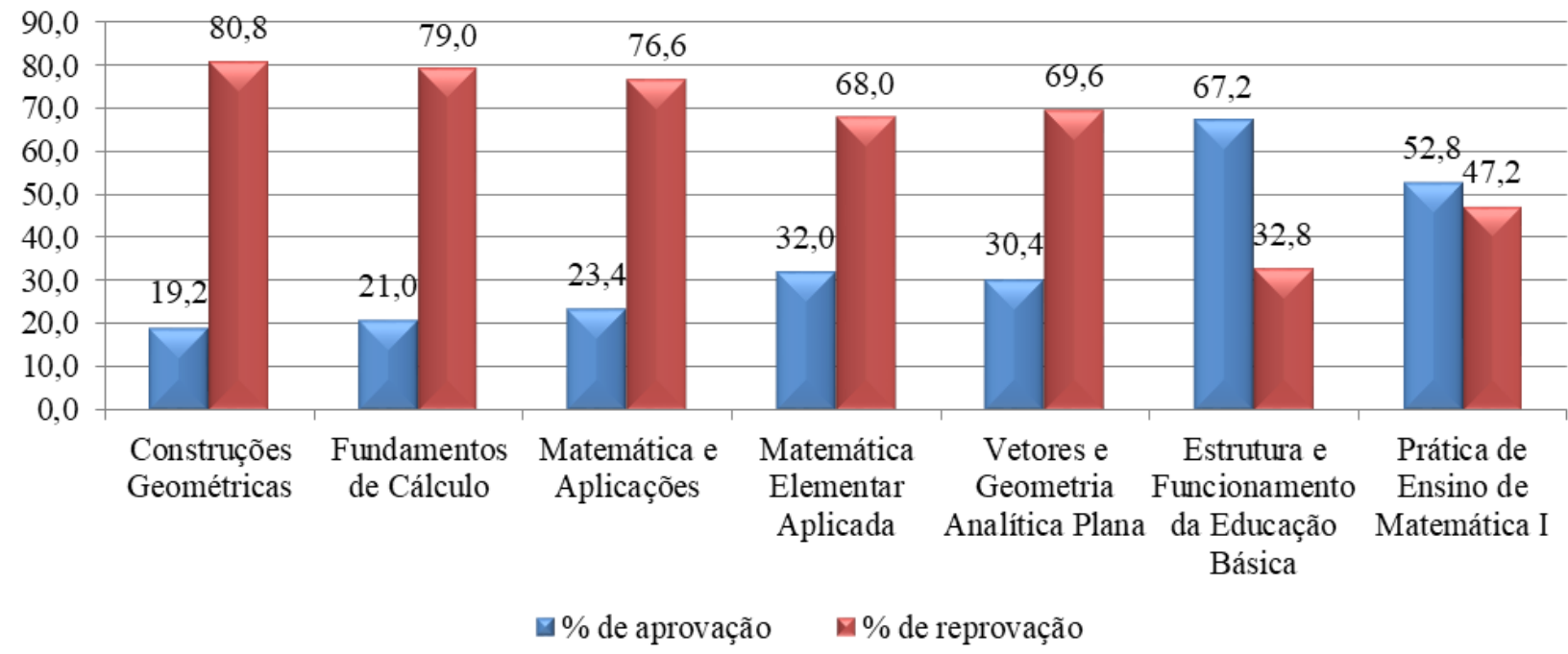

Fonte: Elaboração própria a partir dos dados coletados na pesquisa

Verifica-se que, dentre o conjunto de alunos que ingressaram na UFGD nos anos de 2006 a 2008, os percentuais de reprovação se apresentaram mais elevados nas disciplinas de conteúdo específico do curso de Matemática. Para os componentes de formação pedagógica e dimensão prática, as taxas de aprovação foram superiores aos de reprovação.

Se considerar os dados já expostos anteriormente, em que a maior taxa de evasão no curso de Matemática foi de $73,1 \%$ no ano de 2008 , verifica-se que algumas disciplinas de conteúdo específico apresentaram percentuais de reprovação superiores a este número. As maiores taxas foram obtidas para as disciplinas de Construções Geométricas (80,8\%), Fundamentos de Cálculo (79\%) e Matemática e Aplicações (76,6\%).

Nesse sentido, passa-se a considerar que as reprovações podem ter atingido não somente o conjunto de alunos evadidos e em permanência prolongada, mas também o grupo de diplomados.

O Gráfico 03 apresenta as mesmas informações do Gráfico 03, delimitando-se o grupo de estudantes evadidos.

Gráfico 03 - Percentuais de aprovação e de reprovação em disciplinas ofertadas no primeiro ano do curso de Matemática- Grupo dos evadidos. UFGD. 2006-2008

\footnotetext{
${ }^{8}$ Considerando as alterações curriculares no curso, os dados serão expostos incialmente para as turmas ingressantes entre 2006 e 2008 e, mais adiante, para a turma ingressante em 2009.
} 


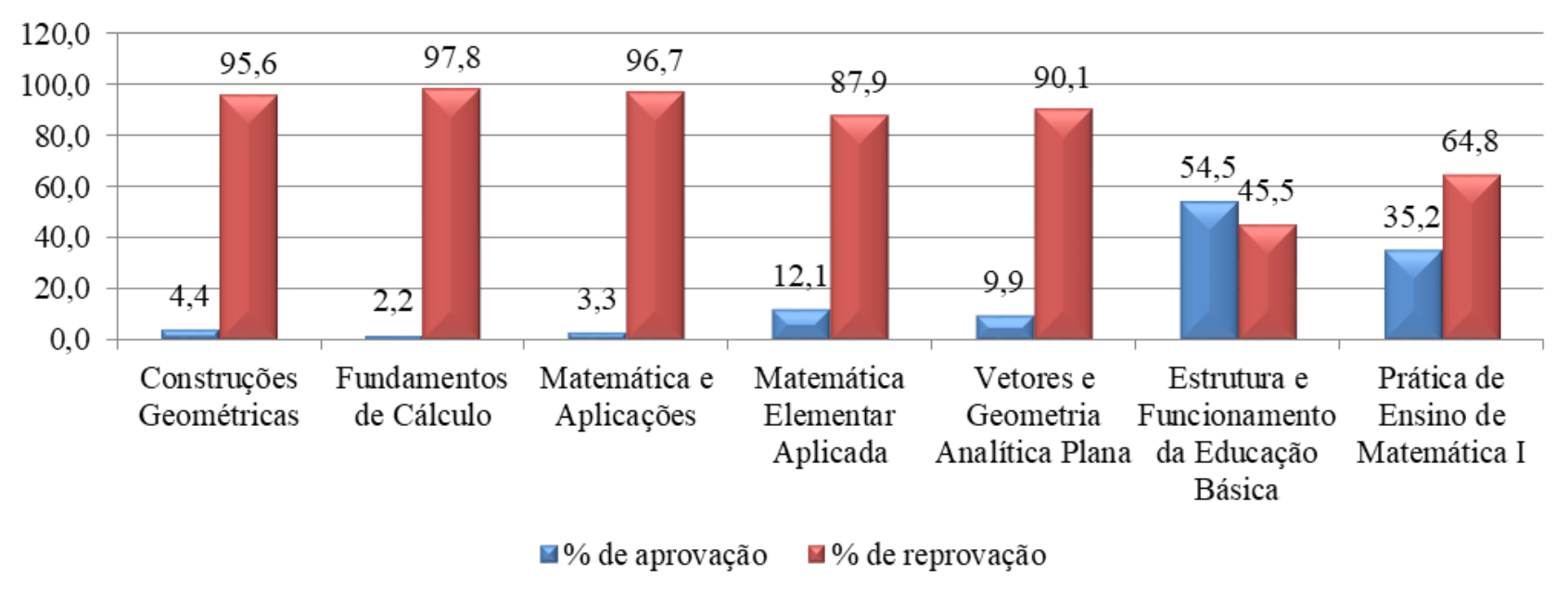

Fonte: Elaboração própria a partir dos dados coletados na pesquisa

Os dados expressos indicam que os percentuais de reprovação se revelaram significativos, sobretudo para as disciplinas de formação específica, em que um número reduzido de estudantes já evadidos do curso obteve aprovação. Para Rafael e Escher (2015), a reprovação na disciplina de Cálculo Diferencial e Integral $^{9}$ tem sido um dos fatores que culminam no "abandono do curso e até mesmo influencia na decisão de não se matricular em um curso de graduação no qual a disciplina seja obrigatória" (p. 3).

Por outro lado, os componentes não relacionados à formação específica apresentaram percentuais de aprovação mais expressivos. A disciplina de Prática de Ensino de Matemática I registrou 35,2\% de aprovação e a de Estrutura e Funcionamento da Educação Básica, 54,5\%.

Nesse sentido, o fracasso inicial em disciplinas próprias das Ciências Exatas pode corresponder a um dos aspectos relevantes para a decisão de abandono do curso.

Para o conjunto de estudantes ingressantes entre 2006 e 2008 que concluíram o curso, os dados de aprovação e de reprovação nas disciplinas ofertadas no primeiro ano são reunidos no Gráfico 04:

Gráfico 04 - Percentuais de aprovação e de reprovação em disciplinas ofertadas no primeiro ano do curso de Matemática - Grupo dos concluintes. UFGD. 2006-2008

\footnotetext{
${ }^{9}$ Similar à disciplina de "Fundamentos de Cálculo", constante no rol de componentes do primeiro ano de curso na UFGD entre 2006 e 2008.
} 


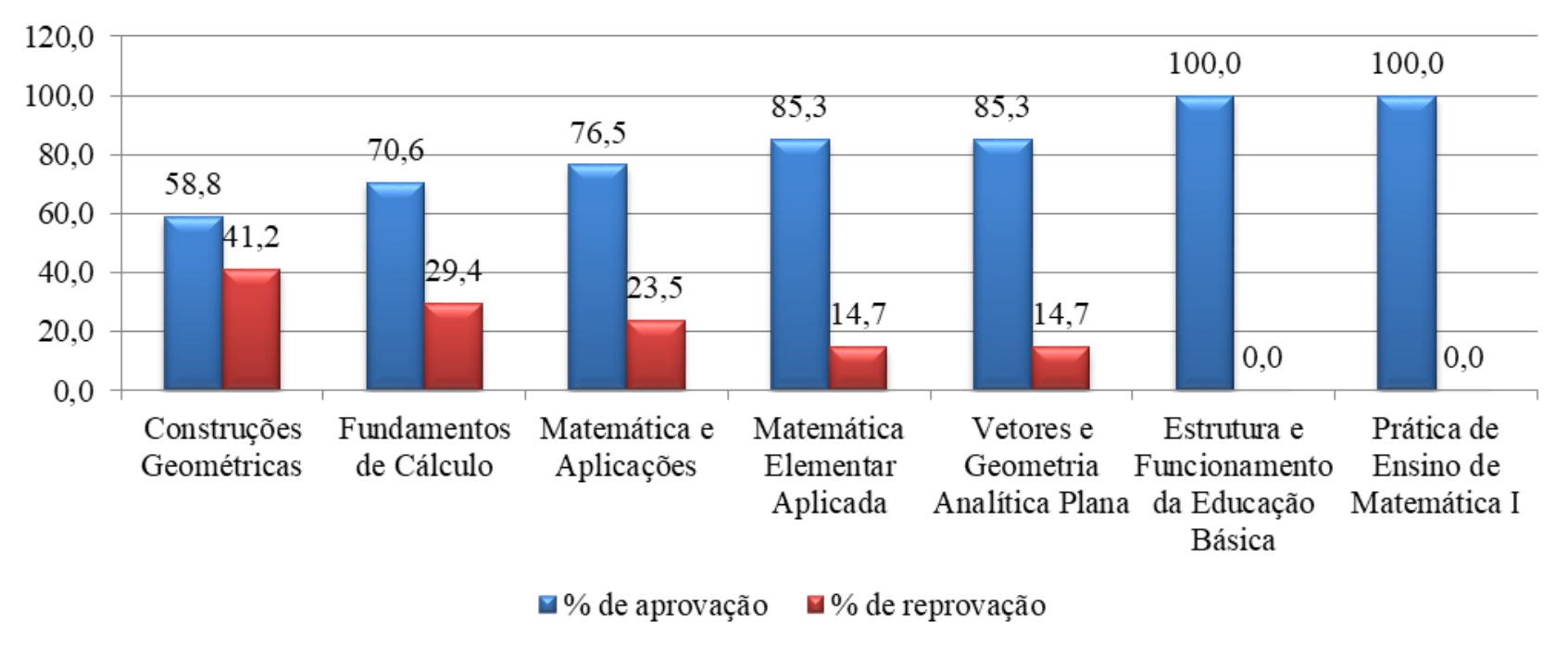

Fonte: Elaboração própria a partir dos dados coletados na pesquisa.

Para o grupo exposto no Gráfico 04, os percentuais de aprovação nos componentes apontados foram significativos, atingindo $100 \%$ para as disciplinas não relacionadas à formação específica do curso de Matemática. Para estas disciplinas, verifica-se que alguns estudantes não obtiveram êxito na primeira vez em que as cursaram, entretanto, as taxas foram expressivamente menores do que os registrados para o grupo de evadidos.

Os percentuais de reprovação dos concluintes foram de 40,6\% em Construções Geométricas, 28,1\% em Fundamentos do Cálculo, 21,9\% em Matemática e Aplicações, 15,6\% em Matemática Elementar Aplicada e 12,5\% em Vetores e Geometria Analítica Plana.

Esses dados permitem corroborar a afirmação de que reprovação induz a evasão, especificamente quando as reprovações incidem nas disciplinas específicas do curso.

Até o ano de 2008, além da forte presença de disciplinas específicas da área de matemática, notoriamente de baixo rendimento pelo conjunto de estudantes que os cursavam, apresentava-se como outro aspecto de impacto na vida acadêmica o fato do curso ser anual, em que o fracasso nas disciplinas ofertadas no primeiro ano levaria o estudante a repeti-las, com duração de no mínimo mais um ano letivo, o que implicaria em ampliação do tempo para a conclusão do curso e, consequentemente, contribuindo para a extensão das taxas de permanência prolongada dos estudantes.

Para os ingressantes em 2009, período a partir do qual se iniciou a implementação do Programa Reuni, adotou-se o regime de créditos semestrais nos cursos de graduação da UFGD, o que pode promover alterações nos percentuais de reprovações.

A partir deste ano, também, a instituição reduziu o número de disciplinas específicas do curso nos primeiros períodos, com o intuito de proporcionar uma formação mais ampla e transdisciplinar aos sujeitos. Este objetivo, por sua vez, embasava parte do processo de implementação da política do Reuni, o que possibilitava aos alunos decidir pela mobilidade acadêmica no caso de não se adaptarem ao curso de ingresso, com o intuito de minorar a evasão no contexto das instituições.

Embora os estudantes pudessem escolher alguns dos componentes a serem cursados, verificou-se uma concentração significativa de matrículas nas disciplinas de "Álgebra Linear e Geometria Analítica", "Fundamentos da Matemática", "Políticas Públicas de Educação", "Ciência e Cotidiano" e "Conhecimento e Tecnologias", do primeiro semestre, e "Fundamentos de Didática", "Introdução ao Cálculo", "Sustentabilidade na Produção de Alimentos e Energia" e "Tecnologias da Informação e 
Comunicação", do segundo semestre. Destas disciplinas, apenas três se referiam a conteúdos específicos do curso de Matemática ${ }^{10}$.

Os dados relacionados à aprovação e à reprovação nas referidas disciplinas são expostos no Gráfico 05:

Gráfico 05 - Percentuais de aprovação e de reprovação em disciplinas ofertadas nos dois primeiros semestres do curso de Matemática. UFGD. 2009

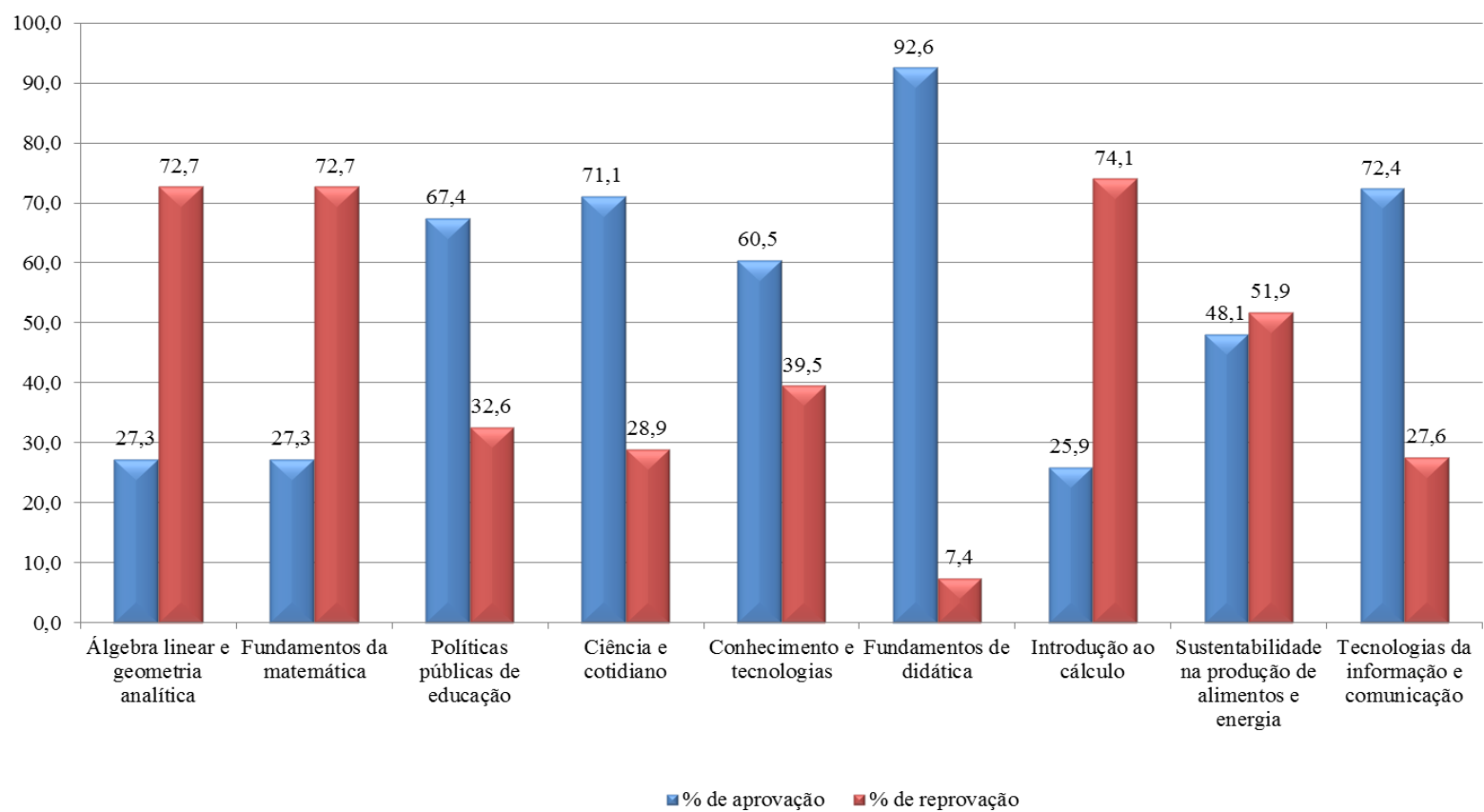

Fonte: Elaboração própria a partir dos dados coletados na pesquisa.

Verifica-se, mais uma vez, que as disciplinas não relacionadas à formação específica do curso apresentaram percentuais de aprovação significativos dentre o conjunto de estudantes que ingressaram por vestibular em 2009. As disciplinas de formação específica continuaram com taxas de reprovação expressivas, sendo estas superiores a $70 \%$.

Entretanto, com a oferta de apenas três componentes de conteúdo específico no primeiro ano do curso e, ao mesmo tempo, com maiores percentuais de aprovação nas demais disciplinas, pode-se pressupor que a reestruturação curricular efetivada na instituição se tratou de um fator positivo para a decisão de continuidade do curso pelos acadêmicos.

Mesmo os estudantes evadidos obtiveram percentuais expressivos de aprovação em alguns componentes curriculares, conforme pode ser visto no Gráfico 06.

Gráfico 06 - Percentuais de aprovação e de reprovação em disciplinas ofertadas nos dois primeiros semestres do curso de Matemática - Grupo dos evadidos. UFGD. 2009

\footnotetext{
10 Tratam-se dos componentes curriculares "Álgebra Linear e Geometria Analítica", "Fundamentos da Matemática" e "Introdução ao Cálculo".
} 


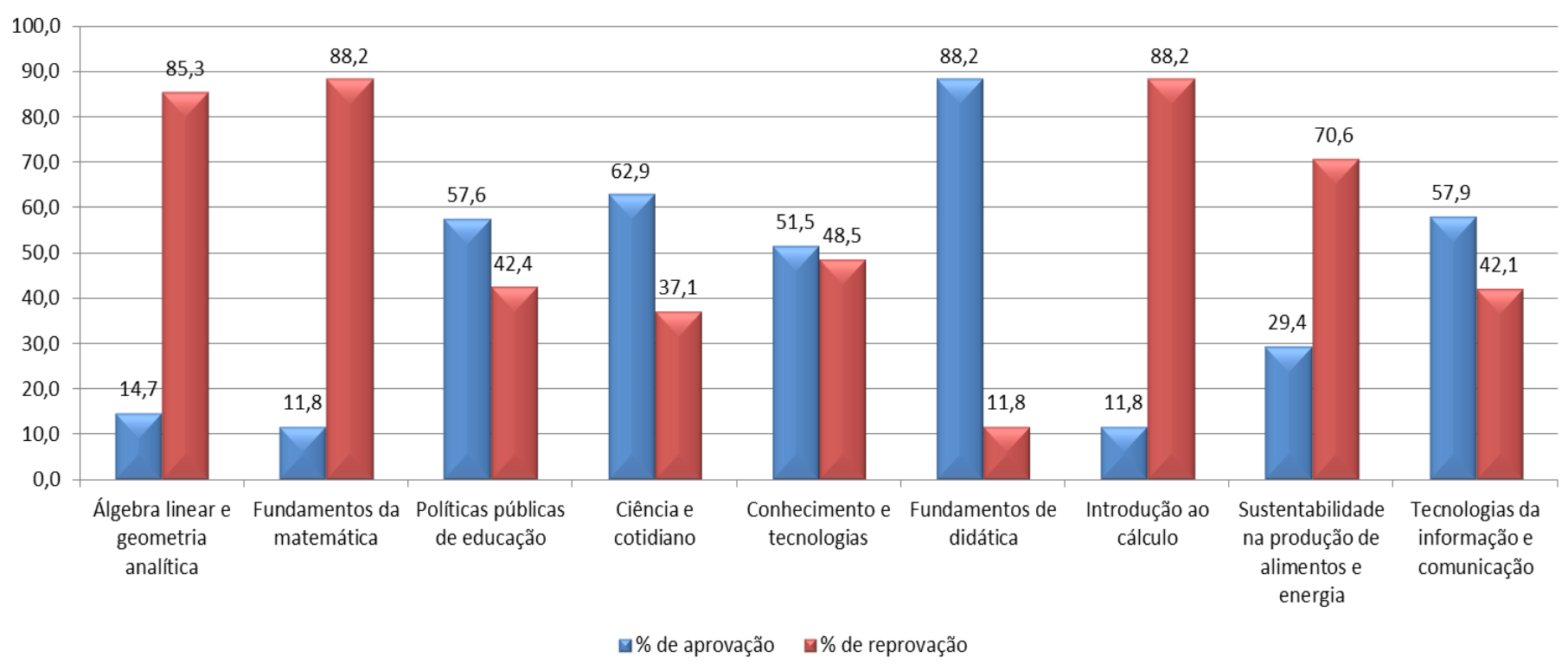

Fonte: Elaboração própria a partir dos dados coletados na pesquisa.

Os estudantes evadidos obtiveram maiores percentuais de reprovação nas disciplinas de Álgebra linear e geometria analítica (82,8\%), Fundamentos da Matemática $(86,2 \%)$ e Introdução ao Cálculo $(85,7 \%)$. Por outro lado, em outras disciplinas as taxas de reprovação foram menores, sendo a mais baixa aquela obtida na disciplina de Fundamentos de Didática $(14,3 \%)$.

Para os concluintes, os resultados se apresentaram diferentes, conforme informações expostas no Gráfico 07:

Gráfico 07 - Percentuais de aprovação e de reprovação em disciplinas ofertadas nos dois primeiros semestres do curso de Matemática- Grupo dos concluintes. UFGD. 2009

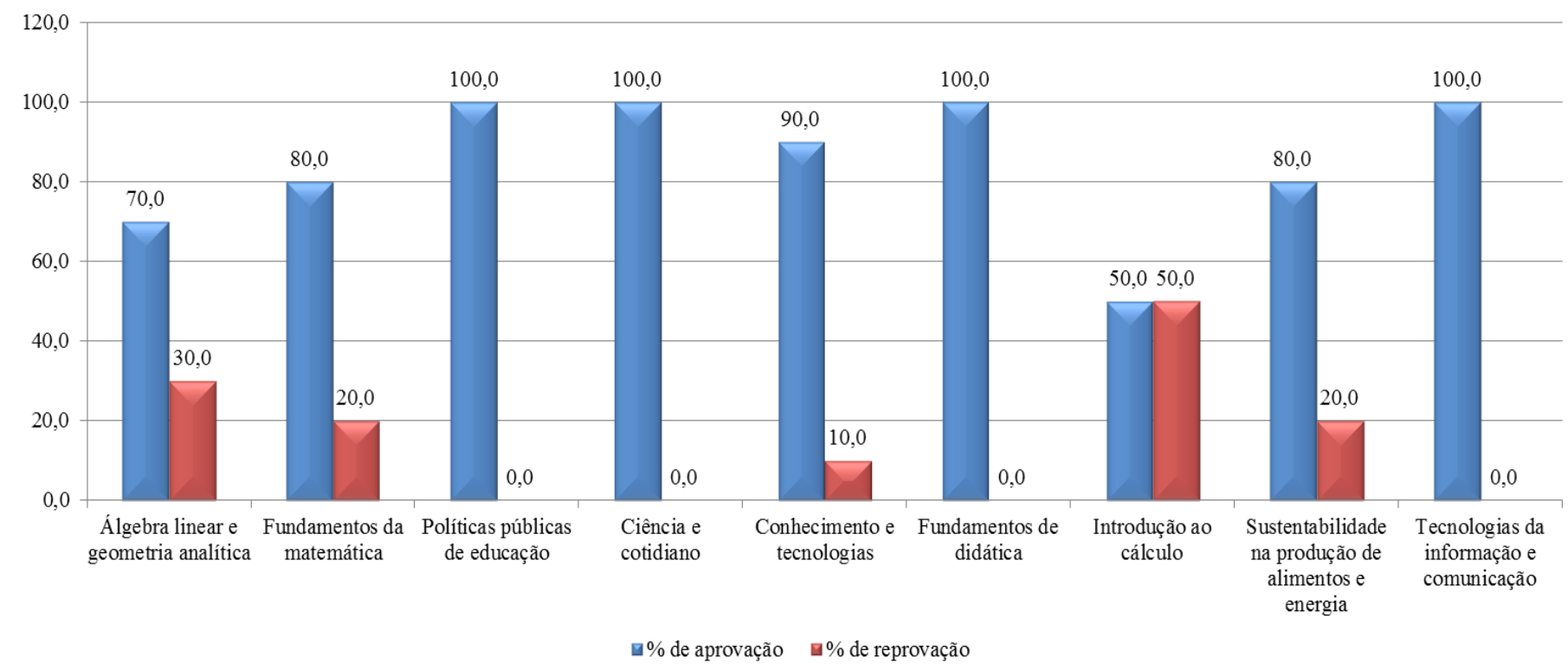

Fonte: Elaboração própria a partir dos dados coletados na pesquisa.

Se contrastados com os dados apresentados anteriormente, pode-se dizer que as taxas de reprovação foram baixas para o conjunto de disciplinas ofertadas no primeiro ano aos alunos já diplomados, ingressantes em 2009. A disciplina com maior percentual de 
reprovação foi a Introdução ao cálculo, em que metade dos alunos não obteve aprovação na primeira vez em que a cursaram.

De modo geral, verifica-se que os alunos evadidos obtiveram maiores percentuais de reprovação nas disciplinas analisadas, quando comparados aos alunos concluintes, sendo que esta situação compreende todo o período de análise da presente pesquisa.

Ao mesmo tempo, também se constata que os maiores percentuais de reprovação se deram em disciplinas de conteúdo específico do curso de Matemática. Ao considerar que a reprovação corresponde a um aspecto importante da trajetória acadêmica, os dados apresentados sugerem que também pode se tratar de um fator crucial para a decisão do estudante de abandonar ou continuar no curso.

A análise se torna um pouco mais acurada ao verificar que há uma diferença no número de disciplinas de conteúdo específico ofertadas em 2006-2008 e em 2009. Até o ano de 2008, das sete disciplinas ofertadas no primeiro ano, cinco delas tratavam de conteúdos próprios da Matemática, sendo que nestes componentes os percentuais de reprovação foram mais expressivos.

Paralelamente a isto, de acordo com os dados apontados na tabela 01, os percentuais de evasão oscilaram de 71,7\% a 73,1\% entre os anos de 2006 e 2008.

No ano de 2009, em que foram ofertadas nove disciplinas, observa-se que apenas três delas tratavam de conteúdo específico do curso de Matemática, nas quais os percentuais de reprovação continuaram a se destacar como os mais significativos quando comparados aos demais componentes. E, a taxa de evasão obtida para a turma ingressante neste ano foi de $64,8 \%$, isto é, menor do que a registrada nos anos anteriores.

Desse modo, entende-se que para o contexto do curso de Matemática as reprovações em disciplinas de conteúdo específico atuam como fatores relacionados à evasão. Ou seja, o aluno ingressa e já no primeiro ano não obtém êxito em vários componentes curriculares, o que contribui para a sua decisão de abandonar o curso. Quando o número de componentes de formação específica diminuiu em 2009, o percentual de evasão também diminuiu. Ainda, verifica-se um grupo de aproximadamente $20 \%$ de estudantes evadidos que abandonaram o curso após o quarto ano.

Assim, pode-se inferir que tanto a reprovação quanto a permanência prolongada, de forma combinada, são fatores que induzem a evasão.

\section{CONSIDERAÇÕES FINAIS}

O objetivo do artigo foi analisar aspectos relacionados à trajetória acadêmica no contexto do curso de Matemática-Licenciatura da UFGD, com vistas a verificar se e como os processos de reprovação e evasão se articulam. De posse dos dados informados pela instituição foi possível construir resultados que permitiram atender ao que se propôs a responder.

Verifica-se que o curso analisado se encontra inserido em um contexto mais amplo, em que os dados estatísticos relacionados à trajetória acadêmica não se apresentam discrepantes em relação aos números encontrados por pesquisadores em outras instituições (BITTAR et al., 2012; SILVA FILHO et al., 2007).

Como se tratam de processos complexos, a interpretação do cenário descrito se associa a uma combinação de fatores, perpassando por questões relacionadas ao perfil socioeconômico dos estudantes, ao mercado de trabalho, ao despreparo acadêmico dos alunos egressos da educação básica, à área do conhecimento, aos aspectos institucionais, às reprovações, dentre outros. 
O presente artigo se debruçou sobre os aspectos referentes às reprovações em componentes curriculares do curso, para então associá-lo aos respectivos percentuais de evasão, inferindo-se que há relação entre tais processos.

A confluência de fatores diversificados pode estar responsabilizando o abandono acadêmico no curso de Matemática, em que a permanência prolongada, desencadeada, sobretudo, por reprovações, configura-se como um fator relevante para a evasão. Contudo, novos estudos são oportunos para a compreensão do peso que o referido fator adquire para a ocorrência da evasão, bem como para o entendimento de outras causas para o fenômeno.

Nesse contexto, indica-se pela realização de mais e novas pesquisas de caráter longitudinal e qualitativo.

\section{REFERÊNCIAS}

ADACHI, Ana Amélia Chaves Teixeira. Evasão e evadidos nos cursos de graduação da Universidade Federal de Minas Gerais. 2009. 214 f. Dissertação (Mestrado em Educação)-Programa de Pós-Graduação em Educação da Universidade Federal de Minas Gerais, Belo Horizonte, 2009.

ARAÚJO, Rhoberta Santana de. Expansão do ensino superior e desenvolvimentismo: limites e contradições sob a hegemonia do capital. Educação e Fronteiras On-Line, Dourados, v. 6, n. 6, p. $93-105,2016$.

BITTAR, Marilena et al. A evasão em um curso de Matemática em 30 anos. EM TEIARevista de Educação Matemática e Tecnológica Iberoamericana, Recife, vol. 3, número 1, p. 1-17, 2012.

BRASIL. Diplomação, retenção e evasão nos cursos de graduação em instituições de Ensino Superior públicas. Brasília: ANDIFES/ABRUEM/SESu/MEC, 1997. 152 p.

MANRIQUE, Ana Lúcia. Licenciatura em matemática: formação para a docência $\mathrm{x}$ formação específica. Educação Matemática Pesquisa, São Paulo, v. 11, n. 3, p. 515-534, 2009.

NUNES, Roseli Souza dos Reis; VELOSO, Tereza Christina Mertens Aguiar. A permanência na educação superior: múltiplos olhares. Educação e Fronteiras On-Line, Dourados, v. 6, n. 6, p. 48-63, 2016.

RAFAEL, Rosane Cordeiro; ESCHER, Marco Antonio. Evasão, baixo rendimento e reprovações em cálculo diferencial e integral: uma questão a ser discutida. In: Encontro Mineiro de Educação Matemática, 7, 2015, Juiz de Fora. Anais... Juiz de Fora: UFSJ, 2015. p. 1-12.

SAMPAIO, Breno et al. Desempenho no vestibular, background familiar e evasão: evidências da UFPE. Economia Aplicada, São Paulo, v. 15, n. 2, p. 287-309, 2011.

SANTOS, Francely Aparecida. Evasão discente no Ensino Superior: estudo de caso de um curso de licenciatura em Matemática. 2012. 246 f. Tese (Doutorado em Educação)Programa de Pós-Graduação em Educação da Universidade Metodista de Piracicaba, Piracicaba, 2012. 
SANTOS JUNIOR, José da Silva; REAL, Giselle Cristina Martins. O acesso à educação superior na Universidade Federal da Grande Dourados: trajetória de estudantes ingressantes entre 2006-2009, Revista Brasileira de Política e Administração da Educação, v. 33, n. 2, p. 467-492, jan./abr. 2017.

SILVA, Antonio Simões; LAMEIRA, Rosangela das Graças Ferreira do Vale; BARBOSA, Katia Aparecida Marangon. Modelo para cálculo de retenção e evasão na educação superior: caso da Engenharia Civil. In: Congresso Brasileiro de Ensino de Engenharia, 42, 2014, Juiz de Fora. Anais... Juiz de Fora: ABENGE, 2014, p. 1-7.

SILVA, Neide Menezes. Sucesso e insucesso na Educação Superior. Recife: Editora Universitária da UFPE, 2012. 211 p.

SILVA FILHO, Roberto Leal Lobo et al. A evasão no Ensino Superior brasileiro. Cadernos de Pesquisa, São Paulo, v. 37, n. 132, p. 641-659, set./dez. 2007.

UFGD. Projeto Pedagógico do curso de Matemática-Licenciatura Plena. Processo $\mathrm{n}^{\circ}$ 23104.005403/2003-33. Dourados, 2003. Disponível para consulta na Coordenadoria de Graduação da Pró-Reitoria de Ensino de Graduação da UFGD.

UFGD. Habilitação Matemática - CEUD. Dourados, 1989. Disponível para consulta na Coordenadoria de Graduação da Pró-Reitoria de Ensino de Graduação da UFGD.

UFGD. Anexo 01 Processo no 23000.005076/88-88. Dourados, 1988. Disponível para consulta na Coordenadoria de Graduação da Pró-Reitoria de Ensino de Graduação da UFGD.

UFGD. Reconhecimento Matemática - Licenciatura Plena CEUD. Dourados, 1990. Disponível para consulta na Coordenadoria de Graduação da Pró-Reitoria de Ensino de Graduação da UFGD.

UFGD. Projeto Pedagógico do Curso de Graduação em Matemática/FACET/UFGDREUNI. Processo no 23005.002258/2008-61. Dourados, 2008. Disponível para consulta na Coordenadoria de Graduação da Pró-Reitoria de Ensino de Graduação da UFGD.

Recebido em: 09/01/2020

Aprovado: $12 / 03 / 2020$ 